Yuniati et al., Afr., J. Infect. Dis. (2018) 12(S): 62-67

https://doi.org/10.2101/Ajid.v12i1S.8

\title{
ANTIBACTERIAL ACTIVITY OF DRACONTOMELON DAO EXTRACTS ON METHICILLIN- RESISTANT $S$. AUREUS (MRSA) AND E. COLI MULTIPLE DRUG RESISTANCE (MDR)
}

\section{Yuniati Yuniati ${ }^{1}$, Nurul Hasanah ${ }^{2}$, Sjarif Ismail ${ }^{3}$, Silvia Anitasari ${ }^{1}$, Swandari Paramita ${ }^{4 *}$}

${ }^{1}$ Department of Microbiology, Faculty of Medicine, Mulawarman University, Samarinda, Indonesia;

${ }^{2}$ Department of Anatomy and Histology, Faculty of Medicine, Mulawarman University, Samarinda, Indonesia; ${ }^{3}$ Department of Pharmacology, Faculty of Medicine, Mulawarman University, Samarinda, Indonesia; ${ }^{4}$ Department of Public Health, Faculty of Medicine, Mulawarman University, Samarinda, Indonesia

\section{*Corresponding Author E-mail: swandariparamita@gmail.com}

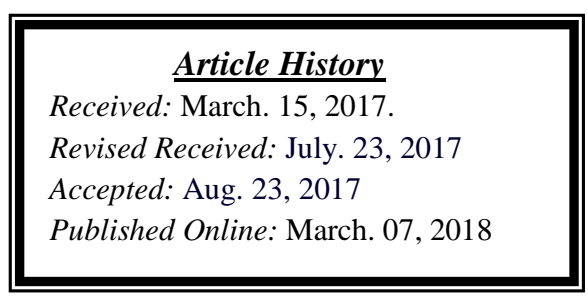

\section{Abstract}

Background: Staphylococcus aureus, methicillin-resistant and Escherichia coli, multidrug-resistant included in the list of antibiotic-resistant priority pathogens from WHO. As multidrug-resistant bacteria problem is increasing, it is necessary to probe new sources for identifying antimicrobial compounds. Medicinal plants represent a rich source of antimicrobial agents. One of the potential plants for further examined as antibacterial is Dracontomelon dao (Blanco) Merr. \& Rolfe. The present study designed to find the antibacterial activity of $D$. dao stem bark extracts on Methicillinresistant S. aureus (MRSA) and E. coli Multiple Drug Resistance (MDR), followed by determined secondary metabolites with antibacterial activity and determined the value of MIC (minimum inhibitory concentration) and MBC (minimum bactericidal concentration).

Materials and Methods: $D$. dao stem bark extracted using 60\% ethanol. Disc diffusion test methods used to find the antibacterial activity, following by microdilution methods to find the value of MIC and MBC. Secondary metabolites with antibacterial activity determined by bioautography using TLC (thin layer chromatography) methods.

Results: $D$. dao stem bark extracts are sensitive to MSSA, MRSA and E.coli MDR bacteria. The inhibition zone is 16.0 $\mathrm{mm}$ in MSSA, $11.7 \mathrm{~mm}$ in MRSA and $10.7 \mathrm{~mm}$ in E. coli MDR. The entire MBC/MIC ratios for MSSA, MRSA and E.coli MDR is lower than 4. The ratio showed bactericidal effects of $D$. dao stem bark extracts. In TLC results, colorless bands found to be secondary metabolites with antibacterial activity.

Conclusion: $D$. dao stem bark extracts are potential to develop as antibacterial agent especially against MRSA and $E$. coli MDR strain.

Key-words: Antibacterial, Dracontomelon dao, MRSA, E. coli MDR

\section{Introduction}

World Health Organization (WHO) published its first ever list of antibiotic-resistant priority pathogens on February 2017. There were twelve families of bacteria that pose the greatest threat to human health. They include Staphylococcus aureus, methicillin-resistant and Escherichia coli, multidrug-resistant (WHO, 2017).

$S$. aureus is a major cause of both hospital- and community-acquired infections, in developed and developing countries. Treatment of $S$. aureus infections is becoming increasingly more complicated due to emerging of various types of antimicrobial resistance worldwide. Methicillin-resistant S. aureus (MRSA) strains are the most concern since these are resistant to all beta-lactam antibiotics and in many cases to other groups of antimicrobials as well, especially in the hospital setting. Overall, rates of MRSA in Southeast Asia ranged from 7\% in the Philippines to 25\% in Malaysia and $39 \%$ in Singapore (Lestari et al., 2012).

E. coli exist as normal flora in originally susceptible to many antimicrobial agents. However, selective pressure by repeated exposure to antibiotics has led to the development of resistance. In Southeast Asia, many studies have assessed antimicrobial resistance among E. coli. The overall prevalence of ampicillin resistance was $\geq 50 \%$, higher than other countries of the world. The fluoroquinolone resistance among gram-negative rod is, however, a phenomenon is seen worldwide (Severin et al., 2012). 
WHO priority pathogen list was drawn up in a bid to guide and promote research and development of new antibiotics, as part of WHO's efforts to discuss growing global resistance to antimicrobial medicines. New antibiotic targeting this priority list of pathogens will help to reduce deaths due to resistant infections around the world (WHO, 2017).

Nature has been a source of medicinal agents for thousands of years and about $80 \%$ of the world's population relies on traditional medicines for their primary health care. Plant materials remain an important resource to combat serious diseases in the world. Due to the most important bioactive constituents which are alkaloids, tannin, flavonoids and phenolic compounds. Advances in identifying new sources of natural products with antimicrobial activities and expanding antibiotic chemical diversity are providing chemical leads for the new antibiotic (Kamath et al., 2016).

As the multidrug-resistant bacteria are increasing, it is necessary to probe new sources for identifying antimicrobial compounds. Medicinal plants represent a rich source of antimicrobial agents. Plants used medicinally in different countries and a source of many potent, powerful drugs. The antibacterial compounds found in plants may prevent bacterial infections by different mechanisms than the commercial antibiotics and may have clinical value in treating resistant microorganisms (Ganapathy and Karpagam, 2016).

One of the potential plants for further examined as antibacterial is Dracontomelon dao (Blanco) Merr. \& Rolfe. D. dao belongs to the Anacardiaceae family. D. dao local name is Pacific Walnut, in Malay known as sengkuang and in Indonesia known as dahu. D. dao is a large tree up to 45-55 meters tall. D. dao tree could be found in Cambodia, China, India, Indonesia, Malaysia, Myanmar, Papua New Guinea, Philippines, Solomon Islands, and Thailand. As medicinal plants, the bark used against dysentery, leaves, and flowers are also employed in traditional medicine (Orwa et al., 2009). As a traditional Chinese medicinal material with a regional feature, it has been widely used to treat various infectious diseases, such as decubitus and skin ulcers (Li et al., 2017). D. dao stem bark used as medicinal plants for diarrhea by Dayak Benuaq people in East Kalimantan, Indonesia (Falah et al., 2013).

Liu et al. (2014) showed an anti-bacterial effect of ethyl acetate extracts from leaves of D. dao on E. coli. Zhao et al. (2015) also showed an anti-bacterial effect of ethyl acetate extracts from leaves of D. dao on $S$. aureus. Ethanol extracts of the leaves of $D$. dao showed anti-Staphylococcus aureus activities. Based on those studies, extracts from the leaves of $D$. dao have possessed anti-infectious potential (Li et al., 2017).

Considering the promising therapeutic potential, our study designed to find antibacterial activity of $D$. dao stem bark extracts on Methicillin-resistant S. aureus (MRSA) and E. coli Multiple Drug Resistance (MDR), followed by determined secondary metabolites with antibacterial activity and determined the value of MIC (minimum inhibitory concentration) and MBC (minimum bactericidal concentration).

\section{Material and Methods \\ Collection and identification of plant material}

The stem bark of D. dao collected from Kutai Kartanegara, East Kalimantan, Indonesia. Identification and voucher specimen deposition of this plant performed at the Dendrology Laboratory, Faculty of Forestry, Mulawarman University, Samarinda, Indonesia with voucher specimen (number: UM 532016).

\section{Processing of plant material and preparation of extracts}

The stem bark of $D$. dao washed with distilled water. The stem bark shed dried, followed by drying in the oven. The sample powdered using a mechanical grinder. Simplicia of stem bark carried in cleaned airtight bottles for maceration in $60 \%$ ethanol for 3 days. All bottles whipped by orbital shaker every day at 2 rpm for 10 minutes and repeated three times. The extracts filtered with micro fiberglass filter in the vacuum pump, followed by freeze-drying process. Plant extracts obtained stored at $4^{\circ} \mathrm{C}$.

\section{Bacteria strains}

Bacterial strains used in this study are MRSA ATCC 25923, MSSA ATCC 43300 and local isolates of E. coli MDR. All these strains cultured in brain heart infusion broth at $37^{\circ} \mathrm{C}$ for 24 hours. Concentrations for all cultures were measured by spectrophotometry.

\section{Antibacterial activity test with disc diffusion method}

Antibacterial activity tested with disc diffusion method as described by Ifesan et al. (2010). Ten microliters of the extracts dissolved in ethanol added to sterile filter paper discs. The discs dried at $70^{\circ} \mathrm{C}$ overnight. The plates of Mueller-Hinton agar applied with $200 \mathrm{uL}$ culture of bacteria. The discs contained extracts seeded on those plates. Ampicillin and oxacillin used as positive controls. The plates then incubated at $37^{\circ} \mathrm{C}$ for 18 hours. The experiments performed in duplicate and the means of the diameters of the inhibition zones calculated. 


\section{Evaluation of MIC and MBC}

Evaluation MIC by standardized broth microdilution method using serially diluted plant extracts, as described by Shaheen et al. (2015). The plates incubated at $37^{\circ} \mathrm{C}$ for 18 hours. MIC showed the lowest concentration of highest dilution of plant extracts that did not give any visible bacterial growth in the microdilution wells. The absence of bacterial growth indicated the $\mathrm{MBC}$ for the respective bacteria. The experiments performed in three times duplication.

\section{Bioautography with TLC (thin layer chromatography)}

Bioautography was carried out by using TLC methods described by Suleiman et al. (2010). Plant extracts loaded on TLC plates in a narrow band and eluted using methanol. The developed plates dried using Laminar flow cabinet. After overnight, the plates mounted on bacteria cultures grown on Mueller-Hinton agar. Colorless bands showed secondary metabolites that inhibited the growth of tested organisms. Visualization is usually carried out by spraying plates with MTT (3-(4,5-dimethylthiazole-2-yl)-2,5-diphenyltetrazolium bromide), as described by Choma and Jesionek (2015).

\section{Data analysis}

Data subjected to statistical analysis for mean and SD at significant level $p<0.05$ using SigmaPlot version 12.5.

\section{Results}

Table 1 showed the antibacterial activity of $D$. dao stem bark extracts. The plant extracts are sensitive to MSSA, MRSA and E.coli MDR bacteria, especially in disc concentration of $3 \mathrm{mg}$ plant extracts. The inhibition zone is $16.0 \mathrm{~mm}$ in MSSA, $11.7 \mathrm{~mm}$ in MRSA and $10.7 \mathrm{~mm}$ in $E$. coli MDR. Table 2 showed MIC and MBC activity of $D$. dao stem bark extracts. MBC/MIC ratio for MSSA is 1.5, MRSA is 1.67 and E. coli MDR is 1.37 . The entire MBC/MIC ratios for MSSA, MRSA and E.coli MDR are lower than 4. The ratio shows bactericidal effects of $D$. dao stem bark extracts. Figure 1 shows there are secondary metabolites with antibacterial activity of $D$. dao stem bark extracts. Colorless bands show of secondary metabolites that inhibited the growth of tested organisms.

Table 1: Antibacterial activity of D. dao stem bark extracts

\begin{tabular}{cccc}
\hline \multirow{2}{*}{ Disc Concentration } & \multicolumn{3}{c}{ Inhibition Zone (mm) } \\
\cline { 2 - 4 } & MSSA & MRSA & ECMDR \\
\cline { 2 - 4 } & Mean \pm SD & Mean \pm SD & Mean \pm SD \\
\hline $0.5 \mathrm{mg}$ & $9.0 \pm 0.8$ & $7.7 \pm 0.5$ & $6.3 \pm 0.5$ \\
$1 \mathrm{mg}$ & $11.7 \pm 1.2$ & $8.7 \pm 0.5$ & $6.7 \pm 0.5$ \\
$2 \mathrm{mg}$ & $14.0 \pm 0.8$ & $10.0 \pm 0.8$ & $7.7 \pm 0.5$ \\
Ampicillin $10 \mu \mathrm{g}$ & $16.0 \pm 0.8$ & $11.7 \pm 0.5$ & $10.7 \pm 0.5$ \\
Oxacillin 1 $\mu \mathrm{g}$ & $18.7 \pm 0.9$ & $6.2 \pm 0.2$ & $6.0 \pm 0.0$ \\
\end{tabular}

Note: MSSA = Methicillin-sensitive Staphylococcus aureus, MRSA = Methicillin-resistant Staphylococcus aureus, ECMDR = Escherichia coli Multiple Drug Resistance

Table 2: MIC and MBC activity of D. dao stem bark extracts

\begin{tabular}{cccc}
\hline \multirow{2}{*}{ Methods } & \multicolumn{3}{c}{ Extracts Concentration (mg) } \\
\cline { 2 - 4 } & MSSA & MRSA & ECMDR \\
\cline { 2 - 4 } & Mean \pm SD & Mean \pm SD & Mean \pm SD \\
\hline MIC & $2.2 \pm 1.0$ & $1.8 \pm 0.4$ & $2.7 \pm 1.0$ \\
MBC & $3.3 \pm 1.0$ & $3.0 \pm 1.1$ & $3.7 \pm 0.8$ \\
\hline
\end{tabular}

Note: MIC = Minimum Inhibitory Concentration, MBC = Minimum Bactericidal Concentration, SSA = Methicillinsensitive Staphylococcus aureus, MRSA = Methicillin-resistant Staphylococcus aureus, ECMDR = Escherichia coli Multiple Drug Resistance 


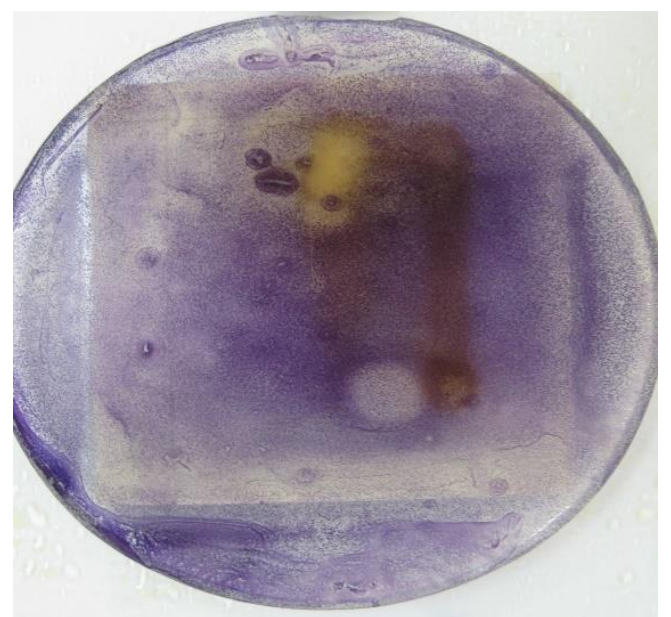

Figure 1: TLC result of $D$. dao stem bark extracts on MRSA with MTT

Note: colorless bands show secondary metabolites that inhibited the growth of MRSA; TLC = thin layer chromatography, $\mathrm{MH}=$ Mueller-Hinton, MTT = 3-(4,5-dimethylthiazole-2-yl)-2,5-diphenyltetrazolium bromide, MRSA = Methicillin-resistant Staphylococcus aureus

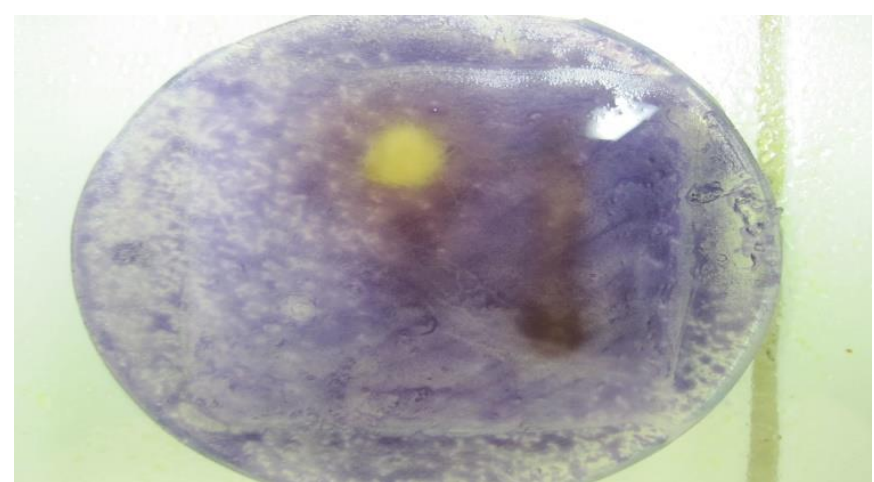

Figure 2. TLC result of $D$. dao stem bark extracts on MSSA with MTT

Note: colorless bands show secondary metabolites that inhibited the growth of MSSA; TLC = thin layer chromatography, $\mathrm{MH}=$ Mueller-Hinton, MTT = 3-(4,5-dimethylthiazole-2-yl)-2,5-diphenyltetrazolium bromide, MSSA = Methicillin-sensitive Staphylococcus aureus

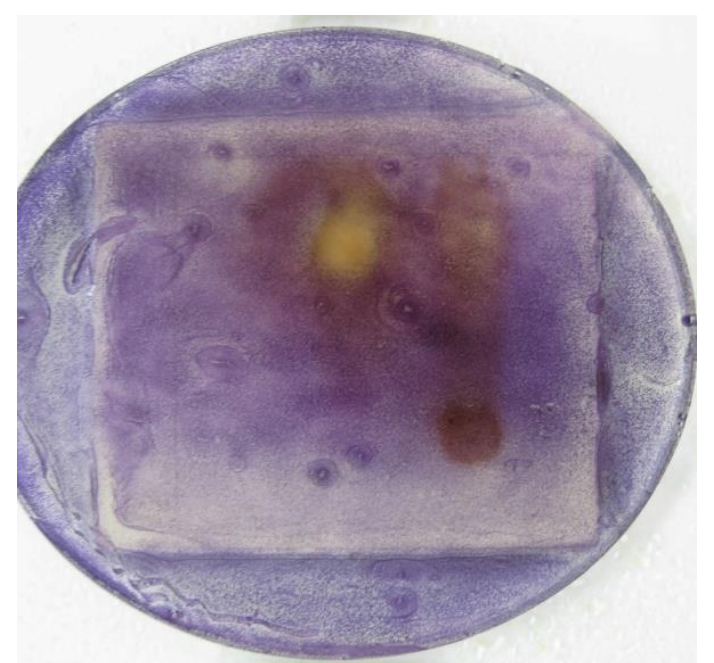

Figure 3: TLC result of $D$. dao stem bark extracts on ECMDR with MTT

Note: colorless bands show secondary metabolites that inhibited the growth of ECMDR; TLC = thin layer chromatography, $\mathrm{MH}=$ Mueller-Hinton, MTT = 3-(4,5-dimethylthiazole-2-yl)-2,5-diphenyltetrazolium bromide, $\mathrm{ECMDR}=$ Escherichia coli multiple drug resistance 


\section{Discussion and Conclusion}

As traditional medicine material in South and Southeast Asia, D. dao has been widely used to treat various infectious diseases. $D$. dao extracts reported to show antimicrobial properties. The synonyms of $D$. dao are Comeurya cumingiana Baill., Dracontomelon brachyphyllum Ridl., Dracontomelon celebicum Koord., Dracontomelon cumingianum (Baill.) Baill., Dracontomelon edule (Blanco) Skeels, Dracontomelon edule Merr., Dracontomelon lamiyo (Blanco) Merr., Dracontomelon laxum K.Schum., Dracontomelon mangiferum (Blume) Blume, Dracontomelon puberulum Miq., and Dracontomelon sylvestre Blume (The Plant List, 2013).

The results of the study showed an antibacterial activity of $D$. dao stem bark extracts. The plant extracts are sensitive to MSSA, MRSA and E. coli MDR bacteria. To the best of our knowledge, this is the first report of antibacterial activity of $D$. dao stem bark extracts to MRSA, MSSA, and E.coli MDR. The results for S. aureus similar to study using the ethyl acetate extracted fraction of $D$. dao leaves. Ethyl acetate fraction had the highest total flavonoid content $(41.86 \%)$, expressed the strongest anti-S. aureus effect with half-inhibitory concentration $\left(\mathrm{IC}_{50}\right) \mathrm{of} 83.93 \mu \mathrm{g} / \mathrm{mL}$ (Zhao et al., 2015). The results for E. coli similar to study using the ethyl acetate extracted fraction of $D$. dao leaves. Ethyl acetate fraction observed to have the strongest anti-E. coli activity with half-inhibitory concentration $\mathrm{IC}_{50}$ of 98.5 $\mu \mathrm{g} / \mathrm{mL}$ (Liu et al., 2014).

To the best of our knowledge, this is the first report of MIC and MBC of $D$. dao stem bark extracts. The results of the study showed MIC and MBC activity of $D$. dao stem bark extracts. MBC/MIC ratios for MSSA, MRSA and E.coli MDR is lower than 4. The ratio shows bactericidal effects of $D$. dao stem bark extracts. A sample is bactericidal when the ratio $\mathrm{MBC} / \mathrm{MIC} \leq 4$ and bacteriostatic when this ratio is $>4$. Antibacterial agents are usually regarded as bactericidal if the MBC is no more than four times the MIC. The MBC is complementary to the MIC since the MIC test demonstrates the lowest level of antimicrobial agent that inhibits growth; the MBC demonstrates the lowest level of antimicrobial agent that results in microbial death (Djeussi et al., 2013).

The results of the study showed secondary metabolites with antibacterial activity of $D$. dao stem bark extracts. Colorless bands show secondary metabolites that inhibited the growth of tested organisms. Results obtained are similar to the study searching for secondary metabolites of $D$. dao. The study by Ragasa et al. (2016) reported isolate of anacardic acid, $\beta$-sitosteryl-3 $\beta$-glucopyranoside-6'- $O$-fatty acid esters, $\beta$-sitosterol, phytol, a mixture of phytyl fatty acid esters and $\beta$-sitosteryl fatty acid esters, chlorophyll a, squalene, long-chain fatty alcohols, and long-chain hydrocarbons from the leaves of $D$. dao.

Further study of the main components of ethyl acetate fraction of extracts $D$. dao leaves which are flavonoids, including Cianidanol, L-Epicatechin, Quercetin, and Luteolin. The result showed that the antibacterial activity of four flavonoids is Luteolin > Cianidanol > Quercetin > L-Epicatechin from the result of the single-factor analysis, which indicated that Luteolin and Cianidanol are very important factors in their antibacterial mechanism. Of note, Quercetin and L-Epicatechin are not the major factors of the antibacterial activity of the extract of the leaves of $D$. dao (Li et al., 2017).

As the conclusion, $D$. dao stem bark extracts are potential to develop as antibacterial agent especially against MRSA and E. coli MDR strain due to the result of the present study. The further in vivo research and mode of its action need to shed light the antibacterial effect.

Competing interest: The authors affirm that there are no competing interests with this study.

\section{Acknowledgements}

We would like to acknowledge Ministry of Health of the Republic of Indonesia for providing funding for this research by RISBINIPTEKDOK Grants in 2011.

\section{References}

1. Choma, I.M. and Jesionek, W. (2015). TLC-Direct Bioautography as a High Throughput Method for Detection of Antimicrobials in Plants. Chromatography. 2: 225-238.

2. Djeussi, D.E., Noumedem, J.A.K., Seukep, J.A., Fankam, A.G., Voukeng, I.K., Tankeo, S.B., Nkuete, A.H.L. and Kuete, V. (2013). Antibacterial activities of selected edible plants extract against multidrug-resistant Gram-negative bacteria. BMC Complementary and Alternative Medicine. 13: 164.

3. Falah, F., Sayektiningsih, T. and Noorcahyati, N. (2013). Diversity and Utilization of Medicinal Plants by Local Community around Gunung Beratus Protection Forest, East Kalimantan. Jurnal Penelitian Hutan dan Konservasi Alam. 10(1): 1-18.

4. Ganapathy, S. and Karpagam, S. (2016). In vitro evaluation of antibacterial potential of Andrographis paniculata against resistant bacterial pathogens Methicillin Resistant Staphylococcus aureus (MRSA) and Multiple Drug Resistant Escherichia coli (MDR E. coli). International Journal of Bioassays. 5(3): 4879-4881.

5. Ifesan, B.O.T., Ibrahim, D. and Voravuthikunchai, S.P. (2010). Antimicrobial activity of crude ethanolic extract from Eleutherine americana. Journal of Food, Agriculture and Environment. 8 (3\&4): 1233-1236. 
6. Kamath, N., Swaminathan, R. and Desai, N. (2016). Antibacterial activity of Indian medicinal plant Moringa oleifera against MRSA and Klebsiella Spp. (ESBL) which are commonly isolated bacteria in hospital environments. International Journal of Applied Research. 2(8): 515-517.

7. Lestari, E.S., Severin, J.A. and Verburgh, H.A. (2012). Antimicrobial Resistance Among Pathogenic Bacteria in Southeast Asia. Southeast Asian Journal of Tropical Medicine and Public Health. 43(2): 385-422.

8. Li, Y., Xia, H., Wu, M., Wang, J., Lu, X., Wei, S., Li, K., Wang, L., Wang, R., Zhao, P., Zhao, Y. and Xiao, X. (2017). Evaluation of the Antibacterial Effects of Flavonoid Combination from the Leaves of Dracontomelon dao by Microcalorimetry and the Quadratic Rotary Combination Design. Frontiers in Pharmacology 8: 70.

9. Liu, S., Zhao, Y., Zeng, N., Liu, T., Zhang, Y., Han, B., Li, J., Wang, L., Wang, R., Gong, M., Li, Y. and Xiao, X. (2014). Antibacterial effect of four extracts from leaves of Dracontomelon dao on Escherichia coli growth using microcalorimetry coupled with principal component analysis. Journal of Thermal Analysis and Calorimetry. 116(1): 491-497.

10. Orwa, C., Mutua, A., Kindt, R., Jamnadass, R. and Anthony, S. (2009). Agroforestry Database: a tree reference and selection guide version 4.0. http://www.worldagroforestry.org/sites/treedbs/treedatabases.asp.

11. Ragasa, C.Y., Vivar, J.L.A., Reyes, M.M.D.L. and van Altena, I.A. (2016). Secondary Metabolites from Dracontomelon dao (Merr. \& Rolfe). Der Pharma Chemica. 8(19): 257-260.

12. Severin, J.A., Lestari, E.L., Kloezen, W., Toom, N.L., Mertaniasih, N.M., Kuntaman, K., Purwanta, M., Duerink, D.O., Hadi, U., van Belkum, A., Verbrugh, H.A. and Goessens, W.H. on behalf of the "Antimicrobial Resistance in Indonesia, Prevalence and Prevention" (AMRIN) study group. (2012). Fecal carriage of extended-spectrum blactamase-producing Enterobacteriaceae among humans in Java, Indonesia, in 2001-2002. Tropical Medicine and International Health. 17(4): 455-461.

13. Shaheen, A.Y., Sheikh, A.A., Rabbani, M., Aslam, A., Bibi, T., Liaqat, F., Muhammad, J. and Rehmani, S.F. (2015). Antibacterial activity of herbal extracts against multi-drug resistant Escherichia

14. coli recovered from retail chicken meat. Pakistan Journal of Pharmaceutical Sciences. 28(4): 1295-1300.

15. Suleiman, M.M., McGaw, L.J., Naidoo, V. and Eloff, J.N. (2010). Detection of Antimicrobial Compounds by Bioautography of Different Extracts of Leaves of Selected South African Tree Species. African Journal of Traditional, Complementary and Alternative Medicine. 7(1): 64-78.

16. The Plant List. (2013). Version 1.1. http://www.theplantlist.org/tpl1.1/record/kew-2777577

17. World Health Organization. (2017). WHO publishes list of bacteria for which new antibiotics are urgently needed. http://www.who.int/mediacentre/news/releases/2017/bacteria-antibiotics-needed/en/

18. Zhao, Y., Liu, S., Qu, F., Wang, J., Hu, Y., Zhang, P., Wang, R., Zhang, Y., Liu, H., Wang, L., Luo, S. and Xiao, X. (2015). Microcalorimetry coupled with principal component analysis for investigating the anti-Staphylococcus aureus effects of different extracted fractions from Dracontomelon dao. Journal of Thermal Analysis and Calorimetry. 120(1): 913-920. 